\title{
Renal sarcoma and associated malignant pulmonary embolism: a report of 2 cases
}

\author{
Jonathan S. Taylor, MD; ${ }^{*}$ Rodney H. Breau, MD; ${ }^{\dagger}$ llias Cagiannos, MD; ${ }^{\dagger}$ Christopher Morash, $M D^{\dagger}$
}

\begin{abstract}
Renal sarcoma with venous tumour thrombus is usually an aggressive malignancy that necessitates complete surgical extirpation to achieve cure. Due to the rarity of these tumours, clinicians rely on case reports to better understand and treat patients with this disease. We recently encountered 2 patients with renal sarcoma who developed malignant pulmonary embolus. Our cases, combined with those previously published, suggest renal sarcoma tumour thrombus is at high risk for spontaneous and intraoperative embolization. This report details our experience and outlines measures that may decrease the rate of venous tumour embolization in patients with sarcoma.
\end{abstract}

CUAJ 2007;1(2):123-5

S arcomas represent approximately $1 \%$ of primary renal neoplasms. To our knowledge, there are only 10 cases in the medical literature of postpubertal patients with primary renal sarcoma associated with inferior vena cava (IVC) tumour thrombus..$^{1-10}$ Of these cases, 3 suffered a malignant pulmonary embolus (PE). ${ }^{4,6,8}$ We present 2 additional cases of renal sarcomas with IVC thrombus and malignant PE.

\section{Case Presentation and Management}

Case 1

A 17-year-old man presented with minor flank trauma and gross hematuria. Magnetic resonance imaging revealed a large right renal mass and associated IVC tumour thrombus (Fig. 1). Renal biopsy suggested highgrade sarcoma. Metastatic workup was negative. The case was discussed at the Children's Hospital of Eastern Ontario pediatric oncology rounds, and it was decided that the best course of management was surgical resection without neo-adjuvant radiotherapy or systemic chemotherapy. Right nephrectomy, thrombectomy and extensive lymph node dissection were performed without apparent complication. Postoperatively, the patient was dyspneic and CT scan of his thorax revealed bilateral PE (Fig. 2). Doppler imaging of his IVC and leg veins revealed no source of bland thrombus, which is highly suggestive of pre- or intraoperative malignant PE. The patients' histopathology was consistent with a high-grade undifferentiated sarcoma with focal rhabdoid differentiation. Immunostaining revealed focal reactivity for $\mathrm{AE} 1$ and $\mathrm{AE} 3$, vimentin and CD99. Negative reactivity was seen for $\mathrm{S} 100$, muscle specific actin, chromogranin and leukocyte common antigen. The patient died 3 months after the surgery. He had diffuse metastatic disease to bone and lung.

\section{Case 2}

A 43-year-old woman presented with dyspnea, hematuria and left flank pain. She had been diagnosed and treated with anticoagulation for a presumed benign PE. Chest and abdominal CT scans revealed a large left renal mass with associated IVC extension (Fig. 3) and bilateral proximal PE (Fig. 4). Pulmonary endarterectomy could not completely remove the malignant emboli, because they had invaded the bronchial walls. Nephrectomy with thrombectomy were undertaken for palliation of local symptoms and Budd-Chiari syndrome. The thrombus invaded the IVC wall and removal was incomplete. Histopathology of both the pulmonary emboli and the kidney tumour were consistent with clear cell sarcoma. Immunostaining was reactive for vimentin and negative for all cytokeratins,

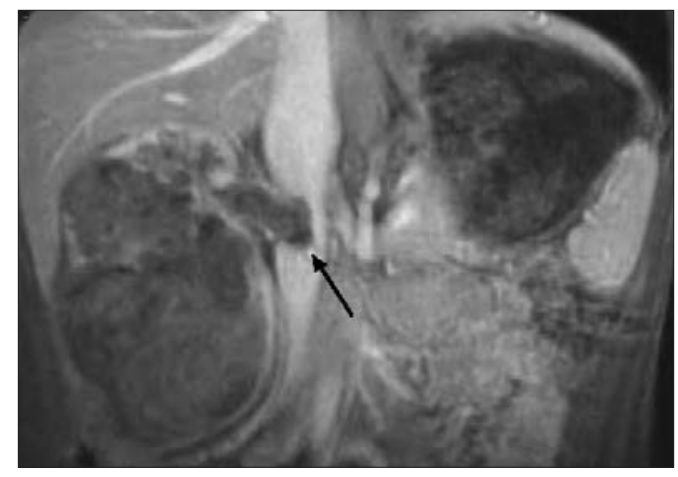

Fig. 1. The arrow indicates a right renal mass with extension into the inferior vena cava. 
S100, HMB45 and epithelial membrane antigen. The patient died 1 month after surgery.

\section{Discussion}

This is the first report to highlight the association of PE with advanced renal sarcoma. Currently, of 12

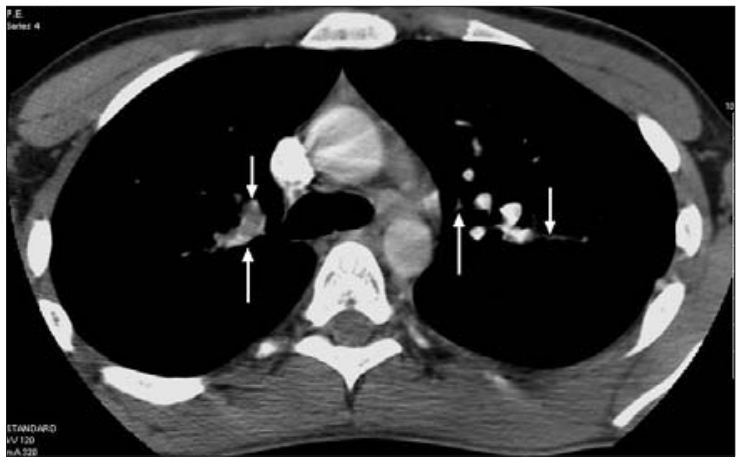

Fig. 2. The arrows indicate bilateral pulmonary emboli.

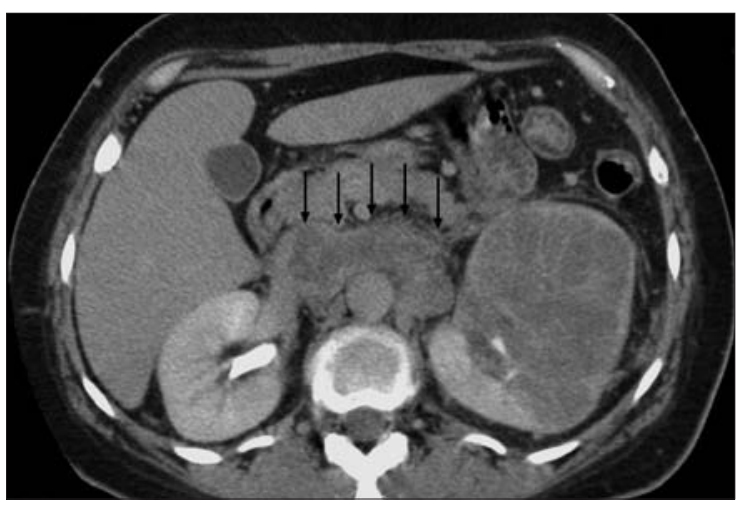

Fig. 3. A left renal mass with extension into the inferior vena cava, as shown by the arrows.

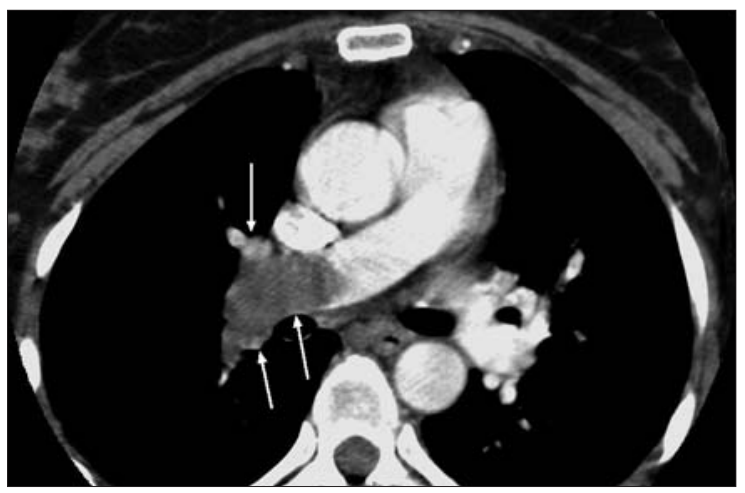

Fig. 4. The arrows show a large embolus in the right pulmonary artery. sarcoma cases with IVC thrombus, 5 (42\%) had malignant PE. This prevalence may be artificially elevated due to publication bias, since unusual or unfortunate events are more frequently reported. Nevertheless, the increased incidence of emboli suggest sarcoma tumours are more susceptible to fragmentation than renal cell carcinoma. ${ }^{11}$

Unfortunately, in the absence of tumour histology, it is not possible to differentiate renal sarcomas from renal cell carcinomas. ${ }^{12}$ Although certain properties, such as young patient age, tumour origin from the renal capsule or renal sinus, decreased tumour vascularity, rapid tumour growth and absence of lymphadenopathy associated with a large primary tumour favour sarcoma, these findings can also be associated with renal cell carcinoma. Therefore, we suggest treating all patients with these characteristics as high risk for malignant PE.

Currently, surgical resection is the primary treatment of organ confined and locally advanced renal sarcoma. However, pediatric patients and patients with unresectable tumours may benefit from radiotherapy and chemotherapy. It is therefore recommended that a multidisciplinary oncology group vet these cases before surgery.

In patients with confirmed or suspected renal sarcoma and venous tumour thrombus, the following recommendations may reduce the risk of malignant embolization:

1) expedient nephrectomy;

2) consideration to preoperative renal angioinfarction to cause thrombus shrinkage; and

3) careful intraoperative thrombus handling with early proximal venous control.

From the * Lethbridge Regional Hospital, Lethbridge, Alta. and the †Division of Urology, Department of Surgery, University of Ottawa, Ottawa, Ont.

This article has been peer reviewed.

Competing interests: None declared.

\section{References}

1. Bhayani SB, Liapis H, Kibel AS. Adult clear cell sarcoma of the kidney with atrial tumor thrombus. J Urol 2001;165:896-7.

2. Chen $\mathrm{PC}$, Chang $\mathrm{YH}$, $\mathrm{Yen} \mathrm{CC}$, et al. Primary renal synovial sarcoma with inferior vena cava and right atrium invasion. Int I Urol 2003; 10:657-60.

3. Karnes RJ, Gettman MT, Anderson PM, et al. Primitive neuroectodermal tumor (extraskeletal Ewing's sarcoma) of the kidney with vena caval tumor thrombus. J Urol 2000; 164:772

4. Ohwada S, Ishikawa S, Kawashima Y, et al. Intraoperative massive pulmonary tumor embolism from clear cell sarcoma in the retroperitoneum: successful treatment using cardiopulmonary bypass. Hepatogastroenterology 2004;51:987-9. 
5. Rosso D, Ghignone GP, Bernardi D, et al. Clear cell sarcoma of the kidney with invasion of the inferior vena cava. Urol Int 2003;70:251-2.

6. Takigawa H, Kagawa $S$, Nakamura $S$, et al. A case of fibrosarcoma of the kidney extending into the inferior vena cava [in Japanese]. Hinyokika Kiyo 1987; 33:936-9.

7. Toyoda Y, Yamashita C, Sugimoto T, et al. Clear cell sarcoma of kidney with tumor extension into the right atrium. J Cardiovasc Surg (Torino) 1998;39:489-91.

8. Chen HT, Chen JT, Hung SW, et al. Primary renal sarcoma with inferior vena cava thrombus presenting with tumor rupture. Zhonghua Yi Xue Za Zhi (Taipei) 2001;64:183-6.

9. Grutzner G, Furst G, Kuhn FP, et al. Retroperitoneal myxoid liposarcoma of the kidney capsule as a cause of Budd-Chiari syndrome [in German]. Aktuelle Radiol 1991;1:308-11.
10. Baba K, Yamaguchi 0 , Nomiya $M$, et al. A case of adult Wilms' tumor with vena caval involvement [in Japanese]. Hinyokika Kiyo 1995;41:369-72.

11. Parekh DJ, Cookson MS, Chapman W, et al. Renal cell carcinoma with renal vein and inferior vena caval involvement: clinicopathological features, surgical techniques and outcomes. J Urol 2005;173:1897-902.

12. Shirkhoda A, Lewis E. Renal sarcoma and sarcomatoid renal cell carcinoma: CT and angiographic features. Radiology 1987;162:353-7.

Correspondence: Dr. Christopher Morash, Division of Urology, Department of Surgery, The Ottawa Hospital - Civic Campus, B3 Urology, 1053 Carling Ave., Ottawa ON KIY 4E9; fax 613 761-5305; cmorash@ottawahospital.on.ca

\section{NOTICE $\bullet$ AVIS}

\section{Voiding diary}

A voiding diary is the most objective way to document a patients voiding profile. The value of this clinical tool is well known. Some 10 years ago, members of the CUA and the CANUP created a standardized voiding calendar for CUA members, including simple explanations for patients, in both official languages, user-friendly and easy to insert in clinical or hospital files. This diary, endorsed by the CUA, was distributed by a company for several years, but distribution ceased when the company left the field of urology.

We are delighted to inform you that an agreement has been reached with Laborie Inc. to resume distribution of this voiding diary, now available for all members in pad or electronic format. Please contact 1-888-522-6743 for pad orders or go to www.laborie.com/resources.html for an electronic format.

\section{Calendrier des mictions}

L'utilisation d'un calendrier des mictions permet de documenter de la façon la plus objective possible le profil mictionnel d'un patient. La valeur de cet outil clinique est bien documentée. II y a près de 10 ans, des membres de l'AUC et de la CANUP ont créé à l'intention des membres de l'AUC un calendrier des mictions standardisé comportant des explications simples aux patients, disponible dans les deux langues officielles, facile à utiliser et à insérer dans les dossiers cliniques ou hospitaliers. Ce calendrier, approuvé par l'AUC, fut diffusé par un laboratoire pendant quelques années, mais la distribution a cessé lorsque la compagnie a quitté le domaine de l'urologie.

Nous sommes heureux de vous informer qu'une entente a été établie avec la compagnie Laborie Inc pour reprendre la distribution de ce calendrier des mictions. Il sera disponible sous format papier ou électronique. Cet outil est donc à nouveau disponible pour tous nos membres. Nous vous invitons à communiquer avec le 1-888-5226743 pour en commander sous forme papier ou www.laborie.com/resources.html pour un accès électronique. 